\title{
Benchmark
}

\section{Comparison of Probe Preparation Methods for DNA Microarrays}

BioTechniques 33:884-888 (October 2002)

\author{
Patrick Farbrother, Silke Müller, Angelika A. Noegel, and Ludwig Eichinger \\ University of Cologne, Köln, Germany
}

Biologists today have the possibility to explore the vast and rapidly increasing amount of DNA sequence data provided by genome and expressed sequence tag sequencing projects (7). The technology used in these projects has improved so greatly that, currently, not only small genomes or those of the greatest importance, such as the human genome, are being sequenced but also other species of interest such as catfish, honeybee, or cotton (for overview, see http://www.tigr.org/tdb/). However, knowing the entire genome of an organism is only the beginning of a long odyssey to understanding the functions of all its genes.

New tools such as DNA microarrays (1) are used to take advantage of all the sequence information. With the highly parallel approach of microarray gene expression analysis, we can try to unravel and understand the complex regulatory networks of living organisms. DNA microarrays have been generated for several organisms $(2,5,8,11,12)$ and will be produced for more and more species, as sequence data become available. The process of creating a new DNA microarray for the entire genome of an organism involves the selection and production of thousands of DNA probes. For spotted DNA microarrays, these probes are usually amplified using PCR (10).

Previously described methods (3) state that concentrations of $500 \mathrm{ng} / \mu \mathrm{L}$ DNA are needed for spotting of microarrays. In our hands, such concentra- tions can only be achieved by multiple PCRs per probe, which lead to higher costs and require considerably more time to produce a new microarray. It has also been reported that probe purification should be done using a filtering method to remove nucleotides and primers, thus achieving higher signalto-noise ratios (6).

Here we report the analysis of a DNA microarray of Dictyostelium discoideum with 90 probes amplified on total genomic DNA and purified in three different ways: $(i)$ probe amplification by a single PCR each and purification by ethanol precipitation; (ii) pooling of five PCRs/probe and purification by ethanol precipitation; and (iii) one PCR/ probe and purification by a silica-gel membrane (QIAvac ${ }^{\circledR}$ PCR Purification Kit; Qiagen, Hilden, Germany).

All PCRs were performed in $100-\mu \mathrm{L}$ reaction volumes in 96-well microplates, and correct amplification was verified by gel electrophoresis and ethidium bromide staining. Partial gene sequences were amplified, and the size of the amplified probes was $509 \mathrm{bp}$ on average. For spotting, the probes were either purified with the QIAvac PCR Purification Kit followed by ethanol precipitation or directly ethanol precipitated, dissolved in $10 \mu \mathrm{L}$ TE with $50 \%$ DMSO (10 mM Tris-HCl, $\mathrm{pH} 8.0,1$ mM EDTA, 50\% DMSO), transferred to 384-well microplates, and stored at $-20^{\circ} \mathrm{C}$ until used. Probes were spotted in duplicates onto poly-L-lysine slides (Sigma, Taufkirchen, Germany) with a
MicroGrid II spotter and MicroSpot2500 split pins (both from BioRobotics, Cambridge, UK), resulting in spots with $140 \mu \mathrm{m}$ diameter. After printing, the spots were dried at room temperature, and the DNA was linked to the slide surface by baking at $80^{\circ} \mathrm{C}$ for $2 \mathrm{~h}$. Microarrays were subsequently washed with $0.1 \%$ SDS and double-distilled water for $1 \mathrm{~min}$, the DNA denatured in double-distilled water at $95^{\circ} \mathrm{C}$ for $2 \mathrm{~min}$, plunged into ethanol, and dried by centrifugation at $235 \times g$.

Target preparation was performed by isolating cytosolic RNA from $D$. discoideum cultures with the RNeasy ${ }^{\circledR}$ Midi Kit (Qiagen), reverse-transcribing $20 \mu \mathrm{g}$ total RNA/reaction in the presence of aminoallyl dUTP with the FairPlay ${ }^{\mathrm{TM}}$ Microarray Labeling Kit (Stratagene, La Jolla, CA USA) and labeling the cDNA with activated $\mathrm{Cy} 3$ and $\mathrm{Cy} 5$ fluorescent dyes (Amersham Biosciences, Uppsala, Sweden). Cy3- and Cy5-labeled targets were mixed, ethanol-precipitated, and dissolved in 15 $\mu \mathrm{L}$ hybridization buffer (9) with 500 $\mu \mathrm{g} / \mathrm{mL}$ fish sperm DNA (Roche Applied Science, Mannheim, Germany) and $2 \mu \mathrm{M}$ Oligo dA 18 -mer. The hybridization mixture was heated to $80^{\circ} \mathrm{C}$ for $10 \mathrm{~min}$, applied to the microarray under a coverslip, and incubated in a hybridization chamber (Corning, Corning, NY, USA) for $15 \mathrm{~h}$ at $37^{\circ} \mathrm{C}$. Afterwards the microarray was washed with $1 \times$ SSC, $0.1 \%$ SDS, and $0.2 \times$ SSC for $10 \mathrm{~min}$ each, quickly plunged in double-distilled water and ethanol, and 
dried by centrifugation. Signal detection was performed with the ScanArray ${ }^{\circledR} 4000 X L$ confocal laser scanner (Perkin Elmer Life Sciences, Wellesley, MA, USA). Images for $\mathrm{Cy} 3$ and $\mathrm{Cy} 5$ were obtained, and the spots were detected and quantified with QuantArray ${ }^{\circledR}$ (Perkin Elmer Life Sciences).

Total signal intensities of all probes, spotted in duplicate, were calculated for the three probe preparation methods. Three slides were used for the evaluation and calculation of standard deviations. As shown in Figure 1, the total intensities are similar. Increasing the concentration of the DNA probes in the spotting solution by pooling five reactions did not result in an increase in fluorescent signal intensity. An increase in total signal intensity by $18 \%$ was observed with probes amplified by one PCR and purified with the QIAvac PCR purification kit.

As the total intensity of the 90 probes is mainly determined by the strong signals, we also evaluated how the different probe preparation methods influence the signal intensities of probes over the full range of signal intensities. Figure 2 displays the signals of the 90 probes ordered by their intensities. For the three methods tested, we obtained similar signal intensities for strongly and weakly expressed genes over two orders of magnitude. The graphs for the $1 \times$ probe concentration purified by ethanol precipitation and silica-gel membrane binding run very much in parallel, while the graph for the $5 \times$ probe concentration shows higher signals for weakly expressed genes. The higher total intensity value for the QIAvac-purified probes (see Figure 1) is due to the slightly higher intensities of the strongly expressed genes. This means that for the tested probe concentrations the number of bound probes is not limiting hybridization, even for tar-

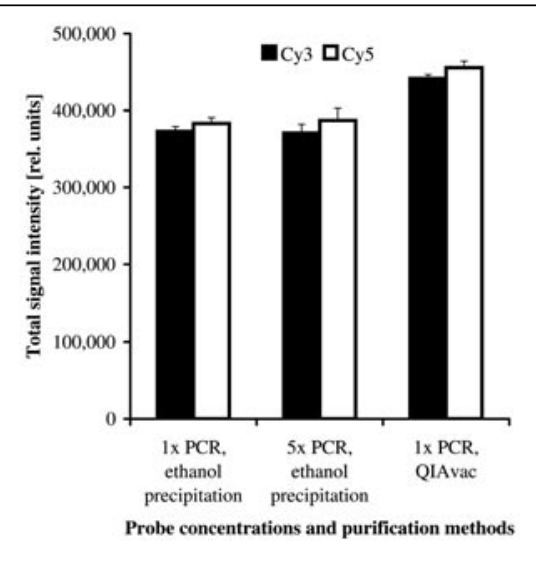

Figure 1. Total signal intensities of 90 probes for Cy3- and Cy5-labeled targets as well as for the three probe preparation methods. Probes were generated by PCR amplification of partial gene sequences on total genomic DNA of $D$. discoideum and purified as described. After background subtraction, the signal intensity for each probe was determined. The total signal intensity is the sum of the single signal intensities of the 90 probes. Average intensities and standard deviations of three microarray slides are shown. 
gets from abundant mRNAs.

There are two possible explanations for this observation. On one hand, at higher probe concentrations, the spotted probes may exceed the DNA binding capacity of the slide surface. If one assumes that the DNA is deposited on the slide as a tightly packed monolayer (4), then approximately $2 \times 10^{7}$ probe molecules with a length of $500 \mathrm{bp}$ could be deposited on a spot of $100 \mu \mathrm{m}$ diameter. Since the delivered spotting volume is around $100 \mathrm{pL}$, a spotting concentration of $100 \mathrm{ng} / \mu \mathrm{L}$ would be sufficient to saturate this spot surface. On the other hand, the number of probes available for hybridization may still surpass the number of labeled targets even if the probe density of a spot is low. This is not only due to the limited number of specific targets, which can be made from, for example, $10 \mu \mathrm{g}$ total RNA as starting material, but also to the limited diffusion speed. Only those targets in the proximity of the matching spot are likely to move and hybridize to the corresponding probe, thereby reducing the number of available targets for hybridization $10^{4}$ - to $10^{5}$-fold (4).

The yield of a single PCR was typically around $7 \mathrm{ng} / \mu \mathrm{L}$, although product concentration varied from 2 to 15 $\mathrm{ng} / \mu \mathrm{L}$. Probes were re-amplified or noted as missing if the product concentration was too low. After concentrating the single or the five PCRs to a spotting volume of $10 \mu \mathrm{L}$, the probe concentration was approximately 50 or 250 $\mathrm{ng} / \mu \mathrm{L}$ on average, respectively. Our results show that a concentration of 50

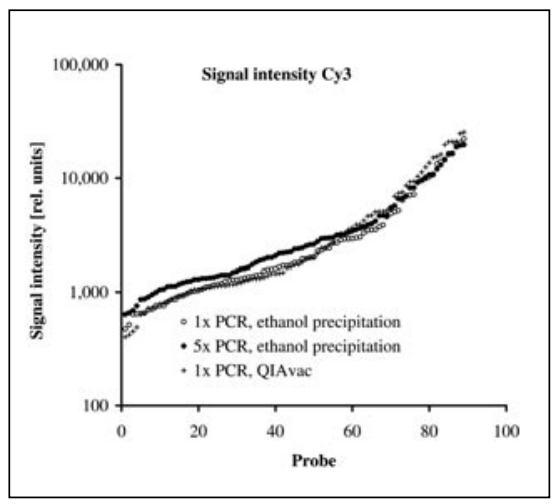

Figure 2. Cy3 signal intensities of the 90 probes and the three probe preparation methods sorted by their intensities. Probe generation and signal intensity determination was done as described in Figure 1. $\mathrm{ng} / \mu \mathrm{L}$, or $1 \times 10^{7}$ probes/spot, was sufficient for hybridization. A higher probe concentration did not result in an increase in total signal intensity, and only slightly higher values were observed for weakly expressed genes. Therefore, the only clear advantage of multiple PCRs is the ability to recoup single PCR failures. In comparison to the use of a silica-gel membrane, the co-precipitation of primers and part of the nucleotides by ethanol possibly reduces the DNA binding capacity of the slide surface, resulting in the slightly lower total intensities with this purification method. No effect of the purification method on the spot morphology could be detected. Both methods resulted in an average spot uniformity of 96 $\%$ (calculated by QuantArray). We conclude that the ability to produce probes for DNA microarrays of sufficient quality and quantity by single PCRs in conjunction with inexpensive and quick ethanol precipitation significantly reduces time and cost in the microarray production process.

\section{ACKNOWLEDGMENTS}

Work in the authors' laboratory is supported in part by the Deutsche Forschungsgemeinschaft grant no. NO 113/15-1 and RO 2114/1-1. Support by Köln Fortune is also acknowledged. We thank Dr. Syltmann, DKFZ Heidelberg, Division of Molecular Genome Analysis, for his many helpful suggestions in the beginning of the microarray project.

\section{REFERENCES}

1.Brown, P.O. and D. Botstein. 1999. Exploring the new world of the genome with DNA microarrays. Nat. Genet. 21:33-37.

2.Chambers, J., A. Angulo, D. Amaratunga, H. Guo, Y. Jiang, J.S. Wan, A. Bittner, K. Frueh, et al. 1999. DNA microarrays of the complex human cytomegalovirus genome: profiling kinetic class with drug sensitivity of viral gene expression. J. Virol. 73:5757-5766.

3.Cheung, V.G., M. Morley, F. Aguilar, A. Massimi, R. Kucherlapati, and G. Childs. 1999. Making and reading microarrays. Nat. Genet. 21:15-19.

4.Duggan, D.J., M. Bittner, Y. Chen, P. Meltzer, and J.M. Trent. 1999. Expression profiling using cDNA microarrays. Nat. Genet. 21: $10-14$.

5.Gingeras, T.R., G. Ghandour, E. Wang, A. Berno, P.M. Small, F. Drobniewski, D. Al- land, E. Desmond, et al. 1998. Simultaneous genotyping and species identification using hybridization pattern recognition analysis of generic Mycobacterium DNA arrays. Genome Res. 8:435-448.

6.Hegde, P., R. Qi, K. Abernathy, C. Gay, S. Dharap, R. Gaspard, J.E. Hughes, E. Snesrud, et al. 2000. A concise guide to cDNA microarray analysis. BioTechniques 29:548562.

7.Lockhart, D.J. and E.A. Winzeler. 2000. Genomics, gene expression and DNA arrays. Nature 405:827-836.

8.Matrajt, M., R.G. Donald, U. Singh, and D.S. Roos. 2002. Identification and characterization of differentiation mutants in the protozoan parasite Toxoplasma gondii. Mol. Microbiol. 44:735-747.

9.Noegel, A., D.L. Welker, B.A. Metz, and K.L. Williams. 1985. Presence of nuclear associated plasmids in the lower eukaryote Dictyostelium discoideum. J. Mol. Biol. 185:447450.

10.Schulze, A. and J. Downward. 2001. Navigating gene expression using microarrays-a technology review. Nat. Cell Biol. 3:E190E195.

11.Swidzinski, J.A., L.J. Sweetlove, and C.J. Leaver. 2002. A custom microarray analysis of gene expression during programmed cell death in Arabidopsis thaliana. Plant J. 30:431446.

12.White, K.P., S.A. Rifkin, P. Hurban, and D.S. Hogness. 1999. Microarray analysis of Drosophila development during metamorphosis. Science 286:2179-2184.

Received 6 June 2002; accepted 5 August 2002.

Address correspondence to:

Dr. Ludwig Eichinger

Institute for Biochemistry I

Medical Faculty

University of Cologne

Joseph-Stelzmann-Str. 52

50931 Köln, Germany

e-mail:ludwig.eichinger@uni-koeln.de

For reprints of this or any other article, contact Reprints@BioTechniques.com 